\title{
6 OPEN ACCESS \\ Fruit and vegetable consumption and all-cause, cancer and CVD mortality: analysis of Health Survey for England data
}

- Additional material is published online only. To view please visit the journal online (http://dx.doi.org/10.1136/jech2013-203500)

Health and Social Surveys Research Group, Department of Epidemiology \& Public Health, UCL (University College London), London, UK

\section{Correspondence to} Dr Oyinlola Oyebode, Health and Social Surveys Research Group, Department of Epidemiology \& Public Health, UCL (University College London), 1-19 Torrington Place, London, WC1E 6BT, UK ; o.oyebode@ucl.ac.uk

Received 10 October 2013 Revised 6 February 2014 Accepted 10 February 2014 Published Online First 31 March 2014

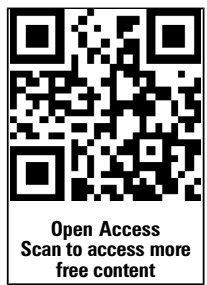

\section{Linked}

- http://dx.doi.org/10.1136/ jech-2014-203981

\section{CrossMark}

To cite: Oyebode 0 , Gordon-Dseagu V, Walker A, et al. J Epidemiol Community Health 2014;68:856-862.

\section{Oyinlola Oyebode, Vanessa Gordon-Dseagu, Alice Walker, Jennifer S Mindell}

\section{ABSTRACT}

Background Governments worldwide recommend daily consumption of fruit and vegetables. We examine whether this benefits health in the general population of England.

Methods Cox regression was used to estimate HRs and $95 \% \mathrm{Cl}$ for an association between fruit and vegetable consumption and all-cause, cancer and cardiovascular mortality, adjusting for age, sex, social class, education, BMI, alcohol consumption and physical activity, in 65226 participants aged 35+ years in the 2001-2008 Health Surveys for England, annual surveys of nationally representative random samples of the noninstitutionalised population of England linked to mortality data (median follow-up: 7.7 years).

Results Fruit and vegetable consumption was associated with decreased all-cause mortality (adjusted HR for $7+$ portions 0.67 ( $95 \%$ Cl 0.58 to 0.78$)$, reference category $<1$ portion). This association was more pronounced when excluding deaths within a year of baseline $(0.58(0.46$ to 0.71$))$. Fruit and vegetable consumption was associated with reduced cancer (0.75 (0.59-0.96)) and cardiovascular mortality (0.69 (0.53 to 0.88$))$. Vegetables may have a stronger association with mortality than fruit (HR for 2 to 3 portions 0.81 (0.73 to 0.89 ) and 0.90 (0.82 to 0.98$)$, respectively). Consumption of vegetables $(0.85$ ( 0.81 to 0.89 ) per portion) or salad (0.87 (0.82 to 0.92$)$ per portion) were most protective, while frozen/canned fruit consumption was apparently associated with increased mortality (1.17 (1.07 to 1.28) per portion).

Conclusions A robust inverse association exists between fruit and vegetable consumption and mortality, with benefits seen in up to 7+ portions daily. Further investigations into the effects of different types of fruit and vegetables are warranted.

\section{INTRODUCTION}

In 1990, the WHO issued recommendations for a minimum daily intake of $400 \mathrm{~g}$ of fruit and vegetables, based on evidence that higher levels were protective against cardiovascular disease (CVD) and some cancers. ${ }^{1}$ This led to the launch of the '5-a-day' fruit and vegetable campaign in the UK in 2003, which has shown some limited success in increasing fruit and vegetable consumption in England. ${ }^{2}$ France and Germany have adopted 5-a-day messages. ${ }^{3}{ }^{4}$ In the USA, the '5-a-day' message was dropped in favour of the 'Fruit and Veggies-More Matters' campaign, in 2007. This was based on 2005 guidelines, ${ }^{5}$ which recommended varying numbers of fruits and vegetable portions depending on individual calorie needs. The Australian government launched the 'Go for $2+5$ ' campaign in $2005,{ }^{6}$ which advises two portions of fruit $(150 \mathrm{~g}$ per portion) and five portions of vegetables $(75 \mathrm{~g}$ per portion) daily (675 g, equivalent to 8.5 UK portions).

In recent years, there has been some controversy about the relationship between fruit and vegetables and mortality, with implications for health policy. The evidence for a protective effect of fruit and vegetables on CVD has been shown in several meta-analyses. ${ }^{7-12}$ This has been strengthened by recent results from a large-scale study using data from the European Prospective Investigation into Cancer and nutrition (EPIC) cohort. ${ }^{13}$

The association with cancer risk is more uncertain. ${ }^{14}{ }^{15}$ Several prospective studies have shown modest $^{16-18}$ or no benefit ${ }^{19}{ }^{20}$ but a comprehensive international review of diet and cancer found that the evidence that fruit and vegetable consumption prevented cancer was 'probable' for cancers of the mouth, pharynx, oesophagus, stomach and lung. ${ }^{21}$

The association between fruit and vegetable consumption and all-cause mortality has recently been examined in the EPIC cohort. $^{22}$ This study found that consumption of fruits and vegetables was inversely associated with all-cause mortality with a HR of 0.90 and CI of 0.86 to 0.94 for the highest quartile of consumption. ${ }^{22}$

A limitation of much of the previous data is that they come from studies of cohorts defined through occupation particularly physicians and nurses who are likely to be health conscious. EPIC includes a large proportion of people who are likely to be health conscious, for example those recruited via blood donations, mammography screening, health insurance programmes, and the Oxford contingent, which was recruited through vegetarian and vegan societies and magazines. ${ }^{23}$ Recent debate has highlighted that there are many confounders associated with selection into non-representative cohorts which may affect the results. ${ }^{24}$ The amount and types of fruit and vegetables eaten by the health conscious may differ from those eaten by the general population. In addition, some constituents of fruit and vegetables may have different effects in the body depending on other aspects of lifestyle (as studies of $\beta$-carotene in smokers show ${ }^{25}$ ).

This study aimed to assess whether fruit and vegetable consumption is associated with all-cause, cancer and cardiovascular mortality in a nationally representative non-institutionalised population.

\section{METHODS}

\section{Participants and data}

Study participants were adults aged 35 years or over within the Health Survey for England (HSE) who gave permission for their data to be linked to 
mortality outcome data. The HSE is an annual survey which uses a multistage stratified design to sample a new, nationally representative random cross section of the free-living population of England each year. Participants are visited by an interviewer who collects demographic and socioeconomic data; collects information on health and health-related behaviours; measures height and weight; and requests consent for data linkage. A nurse then visits participants who agree, to take additional measurements (eg, waist circumference, blood pressure), collect biological samples (eg, blood) and record information on medication use. A detailed description of the HSE has been reported elsewhere. ${ }^{26}$ Research ethics approval was obtained from the relevant committees prior to each survey. Participants gave informed consent before taking part. Response rates varied by year from $72-74 \%$ of eligible households participating in 2001-2006 to 64\% in 2007 and 2008. Within co-operating households, $88-89 \%$ of adults (aged $16+$ years) were interviewed in 2001-2008, with lowest response rates at ages 16-34 years.

Since 2001, HSE participants have been asked about fruit and vegetable consumption on the previous day (the $24 \mathrm{~h}$ from midnight to midnight). Participants are asked about all vegetables and fresh, canned and frozen fruit, as well as salad, pulses, dried fruit and fruit juice/smoothies they have consumed (see web appendix), including dishes made mainly from fruit or vegetables ('composites'). Participants' responses are coded into portion sizes as defined by the Department of Health. ${ }^{27} \mathrm{~A}$ maximum of one portion of pulses, one of fruit juice or a smoothie, and one of dried fruit can contribute to the total daily portions of fruit and vegetables.

Data from HSE years 2001-2008, linked to UK mortality data up to the first quarter of 2013, were analysed for this study. Only participants recruited as part of the core sample (designed to be representative of the national population) were eligible; participants recruited as part of a boost were excluded. Date of death was known to the nearest quarter and entry into the study to the nearest month. NatCen Social Research, the data holders, undertook the data linkage and categorisation of the mortality variables. Two thousand six hundred and eighty-two cases (4\%) were excluded from this study due to missing information on fruit and vegetable consumption. These participants were older but otherwise similar to those included in the study. A further 13 cases $(0.02 \%)$ were dropped due to errors in the dates, leaving a total of 65226 participants.

\section{Statistical analysis}

The outcome measures were all-cause, cancer and CVD mortality. HRs and 95\% CI were calculated using Cox regression for daily portions of fruit and vegetables. Plots of Schoenfeld residuals were used to test the assumption of proportional hazards. Mortality was also examined in relation to fruit portions and to vegetable portions consumed. These were categorised with less than one portion as the reference category, then categories increasing by two portions daily with the highest category defined pragmatically, limited by the low number of participants eating larger quantities. For examination of the association between specific types of fruit and vegetables and mortality, these were treated as continuous variables.

Other variables included in the analysis were age (35-44 years, 45-54 years, 55-64 years, 65-74 years and 75+ years), sex, smoking status (current smoker, ex-regular smoker, never smoked regularly) and social class of the head of household (manual, non-manual, other). Education (degree or equivalent qualification, other, no qualification), measured body mass index (BMI) $\quad\left(<20 \mathrm{~kg} / \mathrm{m}^{2}, \quad 20-24.9 \mathrm{~kg} / \mathrm{m}^{2}, \quad 25-29.9 \mathrm{~kg} / \mathrm{m}^{2}\right.$, $\geq 30 \mathrm{~kg} / \mathrm{m}^{2}$ ), physical activity (as maximum activity intensity level in the past 4 weeks: inactive, light activity, moderate activity, vigorous activity) and alcohol consumption on heaviest drinking day in the previous week (non-drinker, drank within limits, drank above limits, drank more than twice the recommended daily limit) were also added to the models as indicated. The same number of participants were included in all analyses, with those who had missing data for a variable coded to a 'missing category' except for the $0.3 \%$ of the sample with missing information on education, who were coded to the 'other' group. Physical activity questions were asked only in 2002, 2003, 2004 and 2006.

Sensitivity analyses were conducted, first by excluding those who died within a year; second, restricting the analysis to those who had never smoked regularly; and third, examining the association of fruit and vegetable consumption restricted to participants from years in which physical activity variables were available. All analyses were undertaken using IBM SPSS Statistics V.21.

\section{RESULTS}

\section{Characteristics of the study cohort}

Median follow-up was 92 months (7.7 years); 4399 deaths were recorded within the study population, $6.7 \%$ of the sample. Of these deaths, 1398 were due to cancer and 1554 to CVD. At baseline, participants' mean age was 56.6 ( $\mathrm{SD} \pm 14.3)$ years. Of the sample population $55.6 \%$ were female; $20.61 \%$ were current smokers; $48.4 \%$ had never smoked cigarettes regularly. Mean daily portions of fruit and vegetables consumed by participants in the study were 3.8 (SD 2.6): 2.3 portions of fruit (SD 2.0 ) and 1.5 portions of vegetables (SD 1.2).

A comparison of the characteristics of participants by the portions of fruit and vegetables consumed is shown in table 1. Fruit and vegetable consumption each increased monotonically across the categories of total fruit and vegetable consumption; the mean consumption of fruit was non-significantly higher than that of vegetables. Those who consumed more fruit and vegetables were generally older, less likely to smoke and more likely to be women, in a non-manual household, with degree level education. The proportion of study participants who were vigorously active in the last 4 weeks increased as more portions of fruit and vegetables were consumed. Each variable in table 1 was significantly associated with portions of fruit and vegetables consumed (all $\mathrm{p}<0.001$ ) with the exception of mean BMI. BMI as a categorical variable was significantly associated with portions of fruit and vegetable consumed $(\mathrm{p}<0.001)$.

\section{Total portions of fruit and vegetables and all-cause mortality}

In the fully adjusted model, fruit and vegetable consumption was associated with all-cause mortality. Those who ate one to less than three portions of fruit and vegetables a day showed significantly greater survival than those eating less than one portion per day (HR $0.8895 \%$ CI 0.80 to 0.95 ) and the HR decreased as portions of fruit and vegetables increased, with those eating seven+ portions of fruit and vegetables daily showing much decreased mortality (HR 0.67 95\% CI: $0.58-$ 0.78). Excluding deaths within a year of baseline strengthened this effect (HR for seven+ portions: $0.58 \mathrm{CI}$ : 0.46-0.71). When only participants from years in which physical activity questions were asked were included in the analyses, the effect of fruit and vegetables on mortality was similarly increased (HR $0.55 \mathrm{CI} 0.41$ to 0.73 ). When the analysis was restricted to never 
Table 1 Characteristics of study participants

\begin{tabular}{|c|c|c|c|c|c|c|}
\hline & \multirow[b]{2}{*}{ All } & \multicolumn{5}{|c|}{ Portions of fruit and vegetables eaten on the previous day } \\
\hline & & $0-<1$ & $1-<3$ & $3-<5$ & $5-<7$ & $7+$ \\
\hline $\mathrm{N}(\%)$ & 65226 & $9897(15.2)$ & $20132(30.9)$ & $18916(29.0)$ & $10244(15.7)$ & $6037(9.3)$ \\
\hline \multicolumn{7}{|l|}{ Age } \\
\hline Mean Age, years (SD) & $56.6(14.3)$ & $54.2(14.4)$ & $56.9(14.7)$ & $57.6(14.4)$ & $57.1(13.7)$ & $55.3(12.8)$ \\
\hline $35-44, \mathrm{n}(\%)$ & $16865(25.9)$ & $3248(32.8)$ & $5306(26.4)$ & 4455 (23.6) & $2337(22.8)$ & $1519(25.2)$ \\
\hline $45-54, \mathrm{n}(\%)$ & $14610(22.4)$ & $2414(24.4)$ & $4385(21.8)$ & $4050(21.4)$ & $2282(22.3)$ & $1479(24.5)$ \\
\hline $55-64, \mathrm{n}(\%)$ & $14130(21.7)$ & $1765(17.8)$ & $4082(20.3)$ & $4233(22.4)$ & $2499(24.4)$ & $1551(25.7)$ \\
\hline $65-74, n(\%)$ & $10829(16.6)$ & $1319(13.3)$ & 3309 (16.4) & $3366(17.8)$ & $1837(17.9)$ & $998(16.5)$ \\
\hline $75+, n(\%)$ & $8792(13.5)$ & $1151(11.6)$ & $3050(15.2)$ & $2812(14.9)$ & 1289 (12.6) & $490(8.1)$ \\
\hline \multicolumn{7}{|l|}{ Sex } \\
\hline Male, n (\%) & $28974(44.4)$ & $4902(49.5)$ & $9276(46.1)$ & 8059 (42.6) & $4241(41.4)$ & $2496(41.3)$ \\
\hline \multicolumn{7}{|l|}{ Social Class } \\
\hline Non-manual, n (\%) & $31275(47.9)$ & 3318 (33.5) & $8834(43.9)$ & $9684(51.2)$ & $5769(56.3)$ & $3670(60.8)$ \\
\hline Manual, n (\%) & $26583(40.8)$ & $5071(51.2)$ & $8905(44.2)$ & $7176(37.9)$ & 3574 (34.9) & $1857(30.8)$ \\
\hline Other, n (\%) & $7368(11.3)$ & $1508(15.2)$ & $2393(11.9)$ & $2056(10.9)$ & $901(8.8)$ & $510(8.4)$ \\
\hline \multicolumn{7}{|l|}{ Education } \\
\hline Degree or equivalent qualification & $10340(15.9)$ & $735(7.4)$ & $2431(12.1)$ & $3206(16.9)$ & $2250(22.0)$ & $1718(28.5)$ \\
\hline Other & $32969(50.5)$ & $4797(48.5)$ & $10080(50.1)$ & $9663(51.1)$ & 5316 (51.9) & $3113(51.6)$ \\
\hline No qualifications & 21917 (33.6) & $4365(44.1)$ & $7621(37.9)$ & $6047(32.0)$ & $2678(26.1)$ & $1206(20.0)$ \\
\hline \multicolumn{7}{|l|}{ Fruit \& vegetable consumption } \\
\hline Mean portions of fruit, $n$ (SD) & $2.3(2.0)$ & $0.2(0.4)$ & $1.2(0.8)$ & $2.5(1.0)$ & $3.8(1.2)$ & $6.1(2.7)$ \\
\hline Mean portions of vegetables, $n$ (SD) & $1.5(1.2)$ & $0.3(0.4)$ & $1.1(0.7)$ & $1.6(0.9)$ & $2.2(1.1)$ & $3.1(1.8)$ \\
\hline \multicolumn{7}{|l|}{ Cigarette smoking } \\
\hline Current Smoker, n (\%) & $13432(20.6)$ & $3860(39.0)$ & $4897(24.3)$ & $2910(15.4)$ & $1137(11.1)$ & $628(10.4)$ \\
\hline Ex-regular smoker, n (\%) & $20130(30.9)$ & $2526(25.5)$ & $6235(31.0)$ & 6035 (31.9) & 3381 (33.0) & $1953(32.4)$ \\
\hline Never regular smoker, $\mathrm{n}(\%)$ & $31546(48.4)$ & $3471(35.1)$ & $8964(44.5)$ & $9949(52.6)$ & $5712(55.8)$ & $3450(57.1)$ \\
\hline Missing, n (\%) & $118(0.2)$ & $40(0.4)$ & $36(0.2)$ & $22(0.1)$ & $14(0.1)$ & $6(0.1)$ \\
\hline \multicolumn{7}{|l|}{ BMI } \\
\hline Mean BMl, kg/m² & $27.7(5.0)$ & $27.7(5.2)$ & $27.7(4.9)$ & $27.7(4.9)$ & $27.6(4.9)$ & $27.6(4.9)$ \\
\hline$<20, \mathrm{n}(\%)$ & $1560(2.4)$ & $327(3.3)$ & $494(2.5)$ & $410(2.2)$ & $206(2.0)$ & $123(2.0)$ \\
\hline $20-24.9, \mathrm{n}(\%)$ & $15970(24.5)$ & $2344(23.7)$ & $4810(23.9)$ & $4647(24.6)$ & $2589(25.3)$ & $1580(26.2)$ \\
\hline $25-29.9, \mathrm{n}(\%)$ & $23168(35.5)$ & $3276(33.1)$ & $7190(35.7)$ & $6796(35.9)$ & 3724 (36.4) & $2182(36.1)$ \\
\hline$\geq 30, \mathrm{n}(\%)$ & $15091(23.1)$ & $2365(23.9)$ & $4700(23.3)$ & $4327(22.9)$ & $2333(22.8)$ & $1366(22.6)$ \\
\hline Missing & $9437(14.5)$ & $1585(16.0)$ & $2938(14.6)$ & $2736(14.5)$ & $1392(13.6)$ & $786(13.0)$ \\
\hline \multicolumn{7}{|l|}{ Physical Activity } \\
\hline Inactive & $2594(4.0)$ & $605(6.1)$ & $954(4.7)$ & $697(3.7)$ & $252(2.5)$ & $86(1.4)$ \\
\hline Light Activity & $2948(4.5)$ & $541(5.5)$ & $955(4.7)$ & $852(4.5)$ & $433(4.2)$ & $167(2.8)$ \\
\hline Moderate Activity & $13658(20.9)$ & $2175(22.0)$ & $4350(21.6)$ & $3863(20.4)$ & $2058(20.1)$ & $1212(20.1)$ \\
\hline Vigorous Activity & $5709(8.8)$ & $583(5.9)$ & $1426(7.1)$ & $1697(9.0)$ & 1170 (11.4) & $833(13.8)$ \\
\hline Missing & $40317(61.8)$ & $5993(60.6)$ & $12447(61.8)$ & $11807(62.4)$ & $6331(61.8)$ & $3739(61.9)$ \\
\hline \multicolumn{7}{|l|}{ Alcohol Intake } \\
\hline Non-drinker or drank no alcohol in preceding 7days & $21275(32.6)$ & $3627(36.6)$ & $6541(32.5)$ & $6007(31.8)$ & $3151(30.8)$ & $1949(32.3)$ \\
\hline Drank under daily limit* & $21047(32.3)$ & $2322(23.5)$ & $6217(30.9)$ & $6556(34.7)$ & $3767(36.8)$ & $2185(36.2)$ \\
\hline Drank over daily limit but less than double the daily limit* & $13639(20.9)$ & $1909(19.3)$ & $4170(20.7)$ & 4091 (21.6) & $2190(21.4)$ & $1279(21.2)$ \\
\hline Drank over double the daily limit* & $8497(13.0)$ & $1855(18.7)$ & $2940(14.6)$ & $2092(11.1)$ & $1031(10.1)$ & $579(9.6)$ \\
\hline Missing & $768(1.2)$ & $184(1.9)$ & $264(1.3)$ & $170(0.9)$ & $105(1.0)$ & $45(0.7)$ \\
\hline \multicolumn{7}{|l|}{ Mortality } \\
\hline Died, n (\%) & $4399(6.7)$ & $815(8.2)$ & $1581(7.9)$ & $1218(6.4)$ & $538(5.3)$ & $247(4.1)$ \\
\hline Died of cancer, $\mathrm{n}(\%)$ & $1398(2.1)$ & $246(2.5)$ & $480(2.4)$ & $394(2.1)$ & $184(1.8)$ & $94(1.6)$ \\
\hline Died of CVD, $\mathrm{n}(\%)$ & $1554(2.4)$ & $265(2.7)$ & $550(2.7)$ & $448(2.4)$ & $208(2.0)$ & $83(1.4)$ \\
\hline Median follow-up, months & 92 & 96 & 92 & 91 & 90 & 91 \\
\hline
\end{tabular}

${ }^{*}$ Daily limit is 3 units for women; 4 units for men. Double daily limit is 6 units for women; 8 units for men.

CVD, cardiovascular disease.

smokers, the association between total portions of fruit and vegetables consumed and all-cause mortality was similar to that in the whole study population although the benefits at seven+ portions appeared diminished.
Total portions of fruit and vegetable consumption and cause-specific mortality

In the fully adjusted model, there was an association between total portions of fruit and vegetable consumption and cancer 
Table 2 Association between portions of fruit and vegetables consumed and risk of death from any cause

\begin{tabular}{|c|c|c|c|c|c|}
\hline \multirow[b]{2}{*}{ Model } & \multicolumn{5}{|c|}{ Portions of fruit and vegetables consumed in the previous day $\mathrm{HRs}(95 \% \mathrm{CI})$} \\
\hline & $0<1 *$ & $1<3$ & $3<5$ & $5<7$ & $7+$ \\
\hline Model $1 \dagger$ & 1 & $0.84(0.77$ to 0.92$)$ & $0.71(0.65$ to 0.77$)$ & $0.63(0.56$ to 0.70$)$ & $0.60(0.52$ to 0.69$)$ \\
\hline Model 2‡ & 1 & $0.88(0.80$ to 0.95$)$ & $0.76(0.69$ to 0.83$)$ & $0.70(0.63$ to 0.79$)$ & 0.67 (0.58 to 0.78$)$ \\
\hline Model 2 excluding deaths within a year $(n=84894 ; D=3753) \S$ & 1 & $0.86(0.79$ to 0.95$)$ & $0.71(0.63$ to 0.81$)$ & $0.64(0.53$ to 0.76$)$ & $0.58(0.46$ to 0.71$)$ \\
\hline Model 2, never-smokers only $(n=43973 ; D=1530) \S$ & 1 & $0.94(0.80$ to 1.10$)$ & $0.76(0.64$ to 0.90$)$ & $0.72(0.60$ to 0.88$)$ & $0.77(0.61$ to 0.97$)$ \\
\hline Model 2, physical activity years only $(n=42857 ; D=2269) \S$ & 1 & 0.83 (0.74 to 0.94$)$ & $0.68(0.58$ to 0.80$)$ & 0.61 (0.48 to 0.76$)$ & 0.55 (0.41 to 0.73$)$ \\
\hline Model 2, overweight and obese only $(n=38262 ; D=2143) \S$ & 1 & $0.86(0.76$ to 0.98$)$ & $0.73(0.64$ to 0.84$)$ & $0.63(0.54$ to 0.74$)$ & $0.63(0.52$ to 0.77$)$ \\
\hline Model 2, normal weight only $(n=15970 ; D=968) \S$ & 1 & $0.93(0.77$ to 1.11$)$ & $0.77(0.63$ to 0.93$)$ & $0.70(0.55$ to 0.89$)$ & $0.52(0.37$ to 0.72$)$ \\
\hline
\end{tabular}

and CVD mortality. There was a possible threshold at five to less than seven portions for cancer (HR 0.75 (0.62 to 0.91$)$ ) but no threshold seen up to seven + daily portions of fruit and vegetables for CVD (HR 0.69 (CI 0.53 to 0.88 ), table 3).

\section{The effect of fruit compared with vegetables}

In the fully adjusted model, there appeared to be a threshold for increasing survival with consumption of three to less than four portions of fruit daily (HR 0.84 (CI 0.76 to 0.93 )). The effect of vegetable consumption was greater, $\mathrm{HR}$ for three+ portions daily $0.68(0.58$ to 0.79$))$. Consuming portions of vegetables conferred significantly greater benefit than portions of fruit at two to less than three and three+ portions daily (table 4).

Fruit consumption was not significantly associated with deaths from cancer or from CVD. Vegetable consumption was significantly associated with reduced CVD and cancer death. Sensitivity analysis, excluding deaths within a year of baseline or conducting the analyses limited to never-smokers only, made little difference to the results.

\section{Specific types of fruit and vegetable consumption and all-cause mortality}

When different types of fruit and vegetables were entered into an adjusted model one at a time as continuous variables, portions of vegetables (HR per portion 0.84 (0.81 to 0.88 ) $\mathrm{p}<0.001)$, salad $(0.86(0.81$ to 0.91$) \mathrm{p}<0.001)$, fresh fruit (0.94 (0.93 to 0.96$) \mathrm{p}<0.001)$ and dried fruit $(0.88$ (0.81 to
0.95) $\mathrm{p}=0.002$ ) showed significant associations with mortality. The portions of frozen/canned fruit also showed a significant association, with those eating more frozen/canned fruit having significantly higher risk of all-cause mortality (1.17 (1.07-1.28)) $\mathrm{p}<0.001)$. These associations were robust when the different types of fruit and vegetables were entered into the adjusted model together.

\section{DISCUSSION}

We found a strong inverse relationship between fruit and vegetable consumption and all-cause mortality which was stronger when deaths within a year of baseline were excluded and when fully adjusting for physical activity. Fruit and vegetable consumption was significantly associated with reductions in cancer and CVD mortality, with increasing benefits being seen with up to more than seven portions of fruit and vegetables daily for the latter. Consumption of vegetables appeared to be significantly better than similar quantities of fruit. When different types of fruit and vegetable were examined separately, increased consumption of portions of vegetables, salad, fresh and dried fruit showed significant associations with lower mortality. However, frozen/canned fruit consumption was apparently associated with a higher risk of mortality.

This is the first study of the effects of fruit and vegetable consumption in a nationally representative population in England. Its main strength is following a random sample of the free-living general national population, rather than a local sample or a

Table 3 Association between fruit and vegetable consumption and cancer or CVD-specific mortality

\begin{tabular}{|c|c|c|c|c|c|}
\hline \multirow[b]{2}{*}{ Model } & \multicolumn{5}{|c|}{ Portions of fruit and vegetables consumed in the previous day HRs $(95 \% \mathrm{CI})$} \\
\hline & $0-<1^{*}$ & $1-<3$ & $3-<5$ & $5-<7$ & $7+$ \\
\hline \multicolumn{6}{|l|}{ Cancer } \\
\hline Number of participants (deaths) & 10607 (169) & $28805(485)$ & $24968(400)$ & $13082(187)$ & 7885 (95) \\
\hline Model $1 \dagger$ & 1 & $0.87(0.75$ to 1.02$)$ & 0.78 (0.66 to 0.92$)$ & 0.71 (0.58 to 0.86$)$ & 0.70 (0.55 to 0.90$)$ \\
\hline Model $2 \ddagger$ & 1 & $0.89(0.76$ to 1.04$)$ & $0.81(0.69$ to 0.95$)$ & $0.75(0.62$ to 0.91$)$ & $0.75(0.59$ to 0.96$)$ \\
\hline \multicolumn{6}{|l|}{ CVD } \\
\hline Number of participants (deaths) & $10607(189)$ & $28805(553)$ & $24968(449)$ & $13082(208)$ & $7885(83)$ \\
\hline Model $1 \dagger$ & 1 & $0.88(0.77$ to 1.03$)$ & $0.78(0.66$ to 0.91$)$ & $0.74(0.61$ to 0.89$)$ & $0.63(0.49$ to 0.80$)$ \\
\hline Model $2 \ddagger$ & 1 & 0.91 (0.78 to 1.05$)$ & $0.82(0.70$ to 0.95$)$ & $0.80(0.66$ to 0.96$)$ & 0.69 (0.53 to 0.88$)$ \\
\hline
\end{tabular}




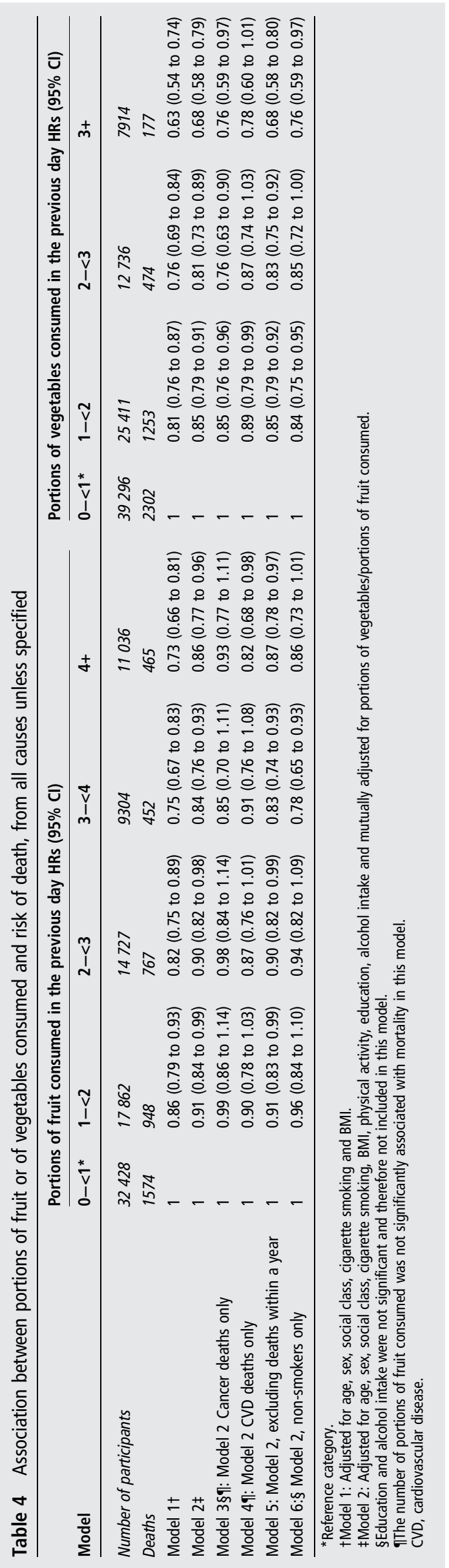

cohort based on occupation or disease status. The main limitation is that measurement of fruit and vegetable intake occurred at only one point in time and relies on self-report. There may be social desirability bias and random error (forgetting) in the recall of fruit and vegetable consumption. Compared with some other studies, which have also assessed intake at a single time, the HSE has probably calculated consumption more precisely, using separate questions to elicit intake in terms of $80 \mathrm{~g}$ portions from a range of relevant sources (web appendix) whereas other studies used 'natural portions' which are imprecise for vegetable servings. ${ }^{76} 18 \quad 20$ Results from the UK National Diet and Nutrition Survey, which collects more detailed dietary data, show a slightly higher mean daily consumption than equivalent HSE years ${ }^{28}$ among its participants, most of whom are from England; thus HSE does not overestimate fruit and vegetable consumption.

Fruit and vegetable consumption measured at baseline may not represent usual, previous or future dietary habits. If changes in dietary habits were most likely to occur in the obese, who also have a higher risk of CVD and cancer, such misclassification bias would tend to make the HR appear closer to unity than it may be in reality.

Seriously ill individuals may eat less due to illness-induced anorexia, or perhaps those with chronic illness receive more health advice and may therefore consume more fruit and vegetables. By excluding deaths within a year of baseline, we attempted to address reverse causality.

Other limitations include the presence of missing data, for example $14.5 \%$ of respondents were missing a valid BMI measurement. All participants were included in all analyses with missing data coded to user-missing categories. In addition physical activity questions were not asked in all years, leading to a large amount of missing data. By restricting the analysis to years in which physical activity questions were asked, we demonstrated that our findings were robust to adjustment for physical activity.

This study has found a strong association, but not necessarily a causal relationship. There are additional unmeasured confounders not included in the analyses, including other aspects of diet. Total energy intake and salt consumption were not measured, and assessments of fat intake were not made in most years, and were therefore not included in these analyses. It is important to note that by not adjusting for total energy intake, our results support the hypothesis that eating fruit and vegetables is associated with decreased mortality not simply through displacing other foods from the diet. Adjustment for fat, fibre or energy intake in the EPIC studies made minimal difference to the findings. ${ }^{1322}$ Our analyses did adjust for BMI, which acts as a proxy for energy balance between intake and expenditure.

For CVD mortality, we found no threshold for a maximal effect within the actual range of consumption, up to seven+ portions. Dauchet et al found a linear relationship for stroke. ${ }^{12}$ He et al found a graded response for stroke in their meta-analysis, with an $11 \%$ risk reduction for three to five servings and $24 \%$ reduction for more than five servings compared with those consuming fewer than three portions. ${ }^{11}$ Similarly, Joshipura et al found the lowest CHD mortality with those eating eight or more portions daily. ${ }^{7}$ Unlike some other published studies, we found a protective effect for all-cancer.

We found that vegetables had a greater effect per portion than fruit, as did Joshipura. ${ }^{7}$ Thus the Australian guidelines may be more appropriate than the UK and European advice. However, Dauchet et al found the reverse. ${ }^{9}$ This may reflect different types of fruit and/or vegetables consumed by different 
Table 5 Association between variety of fruit and vegetable consumed and risk of death, from all causes

\begin{tabular}{|c|c|c|c|c|}
\hline $\begin{array}{l}\text { Type of fruit or vegetable } \\
\text { consumed }\end{array}$ & $\begin{array}{l}\text { HR per portion adjusted for } \\
\text { age, sex, social class, } \\
\text { cigarette smoking and BMI }\end{array}$ & $\mathrm{p}$ Value & $\begin{array}{l}\text { HR per portion adjusted for age, sex, social } \\
\text { class, cigarette smoking, BMI and all other } \\
\text { fruit and vegetable variables }\end{array}$ & p Value \\
\hline Vegetables & 0.84 (0.81 to 0.88 ) & $<0.001$ & 0.85 (0.81 to 0.89$)$ & $<0.001$ \\
\hline Salad & 0.87 (0.82 to 0.92 ) & $<0.001$ & 0.87 (0.82 to 0.92$)$ & $<0.001$ \\
\hline Vegetables in composites & 0.92 (0.82 to 1.02 ) & 0.10 & $0.92(0.82$ to 1.02$)$ & 0.10 \\
\hline Pulses & 0.95 (0.88 to 1.03$)$ & 0.20 & 0.95 (0.88 to 1.03$)$ & 0.20 \\
\hline Fresh Fruit & 0.96 (0.95 to 0.98 ) & $<0.001$ & 0.96 (0.95 to 0.98 ) & $<0.001$ \\
\hline Dried fruit & 0.91 (0.84 to 0.99 ) & 0.03 & 0.91 (0.84 to 0.99$)$ & 0.03 \\
\hline Fruit in composites & $0.93(0.84$ to 1.03$)$ & 0.17 & 0.93 (0.84 to 1.03$)$ & 0.17 \\
\hline Fruit juice & $0.97(0.91$ to 1.04$)$ & 0.40 & $0.97(0.91$ to 1.04$)$ & 0.40 \\
\hline Frozen/canned fruit & 1.17 (1.07 to 1.28$)$ & 0.001 & 1.17 (1.07 to 1.28$)$ & 0.001 \\
\hline
\end{tabular}

populations, and merits further consideration, particularly given current interest in the role of fructose in driving obesity. ${ }^{29-31}$ When individual types of fruit and vegetables were examined, portions of fresh vegetable, salad, fresh and dried fruit showed significant negative associations with all-cause mortality. It has been suggested that some fructose consumption in levels provided by fruit may be beneficial for glycaemic control. ${ }^{32} 33$ It is also the case that salad, fresh fruit and some vegetables are likely to be consumed raw. Raw vegetables have been shown by others to have a stronger inverse association with mortality than cooked vegetables. ${ }^{22}$

In these analyses, consuming frozen/canned fruit was associated with an increased risk of mortality. As far as we know, no other studies have shown this result. This may be due to confounding for example by (poor) access to fresh groceries in deprived areas or among people with pre-existing ill-health or a more hectic lifestyle. These confounding aspects are not covered by the adjustments made in our analyses; further adjustment with other socioeconomic or dietary measurements may demonstrate that this apparent effect is due to confounding. Community level barriers may have an effect on diet independent of social class or education. ${ }^{34}$ Nutritionally, frozen fruit is generally held to be equivalent to fresh fruit. However, most canned fruit contains high sugar levels; fruit packed not in syrup but in fruit juice (which still contains fructose but less sugar overall) is less available and more expensive. Because of the questions asked, consumption of canned fruit cannot be distinguished from frozen fruit. Analysis of National Diet and Nutrition Survey data would enable examination of dietary patterns to elucidate, albeit on smaller samples, the relative contributions of frozen and of canned fruit to 'frozen and canned' consumption, and of the overall dietary patterns and other characteristics of those who eat frozen and canned fruit, to examine possible explanations for this unexpected finding.

The WHO report stated explicitly in relationship to the recommended intake for fruit and vegetables: "Population nutrient goals have been set judgementally rather than on the basis of specific evidence as to the necessary level of intake". ${ }^{1}$ The upper limit at which the protective effect of fruit and vegetables is maximised is unknown; the WHO recommendation was chosen based on the highest level of consumption observed in studies showing evidence of a protective effect (thus reflecting a level at which the effect is known to continue, and is known to be achievable).

We have shown that those eating seven or more portions of fruit and vegetables daily have the lowest risk of mortality from any cause. The majority of adults in the HSE 2007 knew they were recommended to eat five portions daily but stated barriers to improving their diet including: difficulty in changing habits, lack of time, cost, lack of motivation and eating what they were given. ${ }^{35}$ Even among participants who perceived their own diet as 'very healthy', over $50 \%$ ate less than five portions of fruit and vegetables daily. ${ }^{35}$ Fruit and vegetable consumption is inversely related to household income. ${ }^{35}$ This is not surprising, given the perception in England that fruit and vegetables are more expensive than unhealthy foods ${ }^{35}$ and that health education without changing the environment in which individual choices are taken, tends to increase inequalities. ${ }^{36}$ With increasing evidence of their health benefits, policy-makers may need to consider broader initiatives to promote fruit and vegetable consumption, particularly vegetables and salad, as with the Australian guidance. In order to have an impact on those who are most socioeconomically disadvantaged, this should move beyond health education, for example, through fiscal policies.

\section{What is already known on this subject?}

- Previous studies of non-representative cohorts demonstrate an association between fruit and vegetable consumption and mortality, although these findings may not be generalisable to the general population.

- An association between fruit and vegetable consumption and cardiovascular disease appears robust, while associations with cancer mortality are uncertain.

- The amount and type of fruit and vegetables with the greatest benefits for health are not known.

\section{What this study adds?}

- Fruit and vegetable consumption is inversely associated with all-cause, cancer and cardiovascular mortality in a nationally representative non-institutionalised population.

- Those eating seven or more portions of fruit and vegetables daily have the lowest risk of mortality from any cause.

- Consumption of vegetables, salad and fresh or dried fruit is robustly associated with decreased mortality.

Acknowledgements The authors thank colleagues at UCL, particularly Alison Moody and Shaun Scholes for statistical advice and Sadie Boniface for expertise on 
alcohol; NatCen Social Research, particularly Cathy Coshall for providing the linked data; the HSE interviewers; and the survey participants.

Contributors JSM had the initial idea; VG-D and 00 prepared the dataset; 00 conducted the analyses; AW and 00 reviewed the literature. All authors contributed to the drafts and approved the final manuscript. 00 is the guarantor of this paper and can affirm that the manuscript is an honest, accurate and transparent account of the study being reported; that no important aspects of the study have been omitted. JM, VGD and 00 had full access to all of the data (including statistical reports and tables) in the study and can take responsibility for the integrity of the data and the accuracy of the data analysis.

Funding The Health Survey for England (HSE) was funded by the Department of Health until 2004 and the Health and Social Care Information Centre (HSCIC) from 2005. 00 is funded by the London Deanery Public Health Training Scheme; VG-D by Diabetes UK, grant number 08/0003752, AW by the London Deanery Foundation Training Scheme; and ISM by the HSCIC to work on the HSE. This project was unfunded. The survey funders played no part in this study or in the decision to publish the findings. The views expressed are those of the authors and not the survey funders.

Competing interests All authors have completed the Unified Competing Interests form at http://www.icmje.org/coi_disclosure.pdf (available on request from the corresponding author) and declare that none of the authors have any financial or non-financial interests that may be relevant to the submitted work.

Ethics approval London (2001-2007) and Oxford B (2008).

Provenance and peer review Not commissioned; externally peer reviewed.

Data sharing statement Anonymised, non-identifiable participant level cross-sectional survey data are freely available for academic researchers and public health staff to download from the UK Data Service. Anonymised participant level data linked to mortality data are available via the NatCen Social Research Data Release Panel. Participants gave informed consent for data linkage for future research.

Open Access This is an Open Access article distributed in accordance with the Creative Commons Attribution Non Commercial (CC BY-NC 3.0) license, which permits others to distribute, remix, adapt, build upon this work non-commercially, and license their derivative works on different terms, provided the original work is properly cited and the use is non-commercial. See: http://creativecommons.org/ licenses/by-nc/3.0/

\section{REFERENCES}

1 World Health Organization. Diet, Nutrition, and the Prevention of Chronic Diseases Geneva: World Health Organization, 1990. http://www.who.int/nutrition/ publications/obesity/WHO_TRS_797/en/index.html (accessed 31 Jan 2013).

2 Health and Social Care Information Centre. Health Survey for England 2011 trend tables. 2012. http://www.ic.nhs.uk/pubs/hse11trendtables (accessed 6 Sep 2013).

3 Programme National Nutrition Santé. Fruits et légumes: au moins 5 par jour. Programme National Nutrition Santé. http://www.mangerbouger.fr/bien-manger/ que-veut-dire-bien-manger-127/les-9-reperes/fruits-et-legumes-au-moins-5-par-jour html (accessed 6 Sep 2013).

4 Biesalski HK. '5 am Tag'-Kampagne: Wissenschaftliche Begründung. Deutsche Gesellschaft für Ernährung. http://www.dge.de/modules.php?name=News\&file= article\&sid=290 (accessed 6 Sep 2013).

5 U.S. Department of Health and Human Services and U.S. Department of Agriculture. Dietary Guidelines for Americans, 2005. 6th edn. Washington, DC U.S. Government Printing Office, 2005:24.

6 Department for Health and Ageing, Australian Government. Go for $2 \& 5$ http://www. gofor2and5.com.au (accessed 6 Sep 2013).

7 Joshipura KJ, Hu FB, Manson JE, et al. The effect of fruit and vegetable intake on risk for coronary heart disease. Ann Intern Med 2001;134:1106-14.

8 Lock K, Pomerlau J, Causer L, et al. The global burden of disease attributable to low consumption of fruit and vegetables: implications for the global strategy on diet. Bull World Health Organ. 2005:83:100-8.

9 Dauchet L, Amouyel P, Hercberg S, et al. Fruit and vegetable consumption and risk of coronary heart disease: a meta-analysis of cohort studies. J Nutr 2006;136:2588-93.
10 He FJ, Nowson CA, Lucas $\mathrm{M}$, et al. Increased consumption of fruit and vegetables is related to a reduced incidence of coronary heart disease: meta-analysis of cohort studies. J Hum Hypertens 2007;21:717-28.

11 He FJ, Nowson CA, MacGregor GA. Fruit and vegetable consumption and stroke: meta-analysis of cohort studies. Lancet 2006;367:320-6.

12 Dauchet L, Amouvel P, Dallongeville J. Fruit and vegetable consumption and risk of stroke: a meta-analysis of cohort studies. Neurology 2005;65:1193-7.

13 Crowe FL, Roddam AW, Key TJ, et al. Fruit and vegetable intake and mortality from ischaemic heart disease: results from the European Prospective Investigation into Cancer and Nutrition (EPIC)-Heart study. Euro Heart J 2011;32:1235-43.

14 Willett WC. Diet and Cancer: one view at the start of the millennium. Cancer Epidemiol Biomarkers Prev 2001;10:3-8.

15 Potter JD. Vegetables, fruit, and cancer. Lancet 2005;366:527-30.

16 Benetou $V$, Orfanos $P$, Lagiou $P$, et al. Vegetables and fruits in relation to cancer risk: evidence from the Greek EPIC cohort study. Cancer Epidemiol Biomarkers Prev 2008:17:387-92.

17 Takachi R, Inoue M, Ishihara J, et al. Fruit and Vegetable Intake and Risk of Total Cancer and Cardiovascular Disease. Japan Public Health Center-based Prospective Study. Am J Epidemiol 2008;167:59-70.

18 Boffetta P, Couto E, Wichmann J, et al. Fruit and vegetable intake and overall cancer risk in the European Prospective Investigation into Cancer and Nutrition. JCNI J Natl Cancer Inst 2010;102:529-37.

19 George SM, Park Y, Leitzmann MF, et al. Fruit and vegetable intake and risk of cancer: a prospective cohort study. Am J Clin Nutr 2009;89:347-53.

20 Hung $\mathrm{HC}$, Joshipura $\mathrm{KJ}$, Jiang $\mathrm{R}$, et al. Fruit and vegetable intake and risk of major chronic disease. JNCI J Natl Cancer Inst. 2004;96:1577-84.

21 World Cancer Research Fund/American Institute for Cancer Research. Food, Nutrition, Physical Activity and the Prevention of Cancer: A Global Perspective. Washington, DC: World Cancer Research Fund, 2007.

22 Leenders $\mathrm{M}$, Sluijs I, Ros MM, et al. Fruit and vegetable consumption and mortality: European prospective investigation into cancer and nutrition. Am J Epidemiol 2013:178:590-602.

23 Riboli E, Hunt KJ, Slimani N, et al. European Prospective Investigation into Cancer and Nutrition (EPIC): study populations and data collection. Public Health Nutr 2002;5:1113-24

24 Ebrahim S, Davey Smith G. Should we always deliberately be non-representative? Int J Epidemiol 2013;42:1022-6.

25 Wright ME, Groshong SD, Husgafvel-Pursiainen K, et al. Effects of beta-carotene supplementation on molecular markers of lung carcinogenesis in male smokers. Cancer Prev Res 2010:3:745-52.

26 Mindell JS, Biddulph J, Hirani V, et al. Cohort Profile: The Health Survey for England. Int J Epidemiol 2013;41:1585-93.

27 Department of Health. 5 A DAY. http://www.nhs.uk/5aday (accessed 06/09/2013)

28 Bates B, Lennox A, Prentice A, et al. eds. National Diet and Nutrition Survey. Headline results from Years 1, 2 and 3 (combined) of the Rolling Programme (2008/2009-2010/11). London: Department of Health, 2012. http://transparency. dh.gov.uk/2012/07/25/ndns-3-years-report/ (accessed 31/01/2013).

29 Lustig RH, Schmidt LA, Brindis CD. The toxic truth about sugar. Nature 2012;482:27-9.

30 Tappy L, Lê KA, Tran C, et al. Fructose and metabolic diseases: New findings, new questions. Nutrition 2010;26:1044-9.

31 Lustig RH. Fructose: metabolic, hedonic, and societal parallels with ethanol. J Am Diet Assoc 2010;110:1307-21.

32 Sievenpiper JL, Chiavaroli L, de Souza RJ, et al. 'Catalytic' doses of fructose may benefit glycaemic control without harming cardiometabolic risk factors: a small meta-analysis of randomised controlled feeding trials. Br J Nutr 2012;108:418-23.

33 Muraki I, Imamura F, Manson JE, et al. Fruit consumption and risk of type 2 diabetes: results from three prospective longitudinal cohort studies. BMJ 2013;28:347.

34 Shohaimi S, Welch A, Bingham S, et al. Residential area deprivation predicts fruit and vegetable consumption independently of individual educational level and occupational social class: a cross sectional population study in the Norfolk cohort of the European Prospective Investigation into Cancer (EPIC-Norfolk). J Epidemiol Community Health 2004;58:686-91.

35 Thompson J. 'Diet and healthy eating'. Chapter 5 In: Craig R, Shelton N, eds. Health Survey for England 2007. Knowledge, attitudes and behaviours. London: NHS Information Centre, 2008;107-48.

36 Capewell SC, Graham H. Will cardiovascular disease prevention widen health inequalities? PLOS ONE 2010;7:e1000320. 